\title{
Biomarkers of cardiovascular injury and stress are associated with increased frequency of ventricular ectopy: a population-based study
}

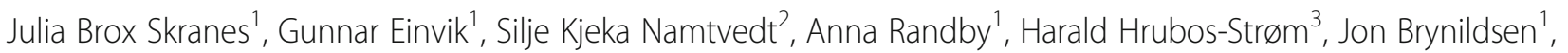
Tor-Arne Hagve ${ }^{4,6}$, Virend K. Somers ${ }^{5}$, Helge Røsjø $\varnothing^{1,6}$ and Torbjørn Omland ${ }^{1,6^{*}}$

\begin{abstract}
Background: Asymptomatic ventricular arrhythmias are common and associated with increased risk of cardiovascular mortality. Cardiac troponins, natriuretic peptides and C-reactive protein (CRP) are also predictive of adverse cardiovascular events in the general population, but limited information is available on the relationship between these biomarkers and ventricular ectopy in a community-based population.

The objectives were to evaluate the associations between ventricular ectopic activity and N-terminal pro-B-type natriuretic peptide (NT-proBNP), high sensitivity-troponin I (hs-Tnl) and hs-CRP in a community-based setting.

Methods: We performed a $24 \mathrm{~h}$ Holter-recording and blood sampling in 498 subjects. Premature ventricular complexes (PVC) were classified as frequent at $>5 / \mathrm{h}$ and the presence of any bigeminy, trigeminy or non-sustained ventricular tachycardia were classified as complex ventricular ectopy. The associations between biomarkers and ventricular arrhythmias were investigated by univariate and multivariate logistic regression analyses.

Results: Frequent PVC's and complex ventricular ectopy were detected in 46 (9\%) and 47 (9\%) participants respectively, and were associated with significantly $(p<0.001)$ higher concentrations of NT-proBNP and hs-Tnl. The association between NT-proBNP and both frequent PVC's $(p=0.020)$ and complex ventricular ectopy $(p=0.001)$ remained significant after adjusting for conventional risk markers in multivariate analyses.

Conclusion: Increased level of NT-proBNP was independently associated with ventricular ectopy, whereas no independent association was observed between hs-Tnl and hs-CRP levels and ventricular ectopy in this communitybased sample.
\end{abstract}

Keywords: Arrhythmias, NT-proBNP, troponin I, C-reactive protein

\section{Background}

Cardiovascular (CV) biomarkers play an increasingly important role in the diagnosis of cardiac diseases, including the use of cardiac troponins to diagnose acute myocardial infarction [1] and B-type natriuretic peptide (BNP) and N-terminal (NT)-proBNP to diagnose heart failure (HF) [2]. Recently, high sensitivity (hs) assays for determination of very low levels of circulating troponins

\footnotetext{
* Correspondence: torbjorn.omland@medisin.uio.no

'Division of Medicine, Akershus University Hospital, Lørenskog, Norway

${ }^{6}$ Institute of Clinical Medicine, University of Oslo, Oslo, Norway

Full list of author information is available at the end of the article
}

have been developed [3], and we and others have demonstrated that hs cardiac troponin I (hs-TnI) and T (hs-TnT) levels are predictive of adverse cardiovascular events in patients with stable coronary artery disease $[4,5]$, as well as in community-based cohorts $[6,7]$. Likewise, BNP and NT-proBNP concentrations are strongly associated with cardiovascular risk in the general population [8] and low-level increments of Creactive protein (CRP), as measured by high-sensitive assays, also predict risk in patients at low or moderate risk for coronary heart disease (CHD) $[9,10]$. 
Sudden cardiac death, often caused by ventricular arrhythmias, is a common cause of death both in patients with established $\mathrm{CHD}$, as well as in the general population [11-13]. Asymptomatic ventricular arrhythmias are commonly observed in community-based samples [14], and have in some studies been linked to increased risk of sudden cardiac death and death from cardiovascular causes $[15,16]$. As the established CV biomarkers are associated with mortality in the general population, these biomarkers may also predict asymptomatic ventricular arrhythmias in the general population. However, currently only sparse data are available concerning the association between $\mathrm{CV}$ biomarkers and the frequency of arrhythmias in community-based cohorts [17]. Accordingly, the objective of the current study was to assess the potential associations between the concentrations of hs-TnI, NT-proBNP and hs-CRP and the frequency of asymptomatic ventricular ectopy in a community-based sample.

\section{Methods}

\section{Study design}

This is a substudy of the Akershus Sleep Apnea Project (ASAP), which is a community-based, crosssectional study conducted in south Eastern Norway. In a two-phased design, we first randomly drew 30000 persons between 30 and 65 years of age from the $\mathrm{Na}$ tional Population Register (Fig. 1). All participants received the Berlin Questionnaire, a standardized questionnaire for classifying the risk for obstructive sleep apnea (OSA) [18], by mail. Of the 16302 (55.7\%) responders, 1772 persons were randomly drawn as a pool for inclusion in phase 2. A 2:1 ratio of high risk:low risk participants according to the Berlin questionnaire in the

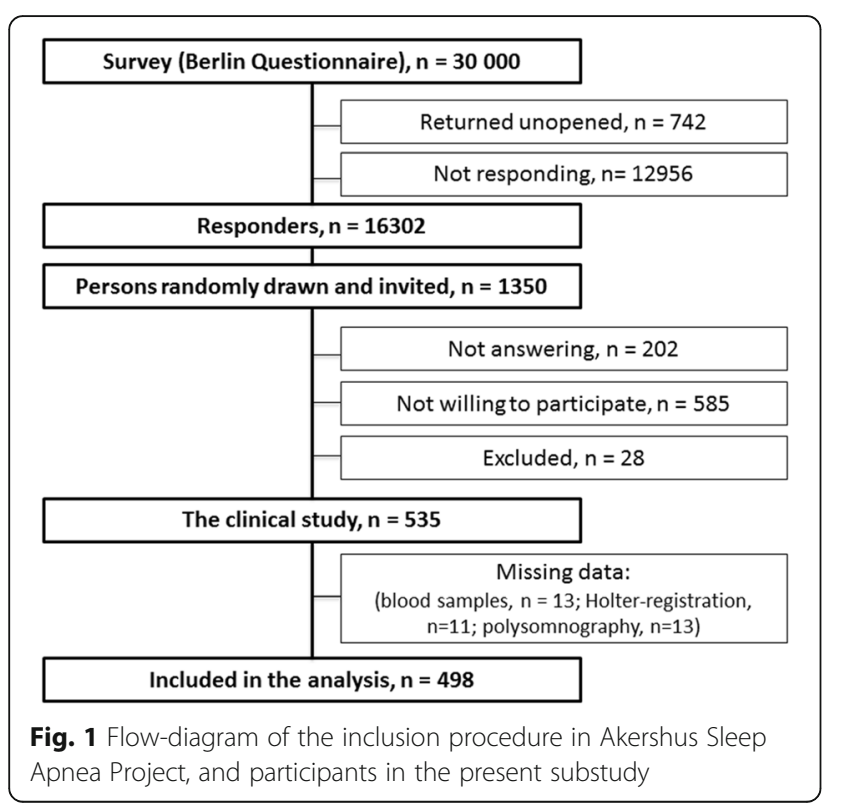

Phase 2 clinical sample resulted in oversampling of participants with risk factors for obstructive sleep apnea, i.e. snoring, daytime sleepiness, obesity and hypertension. In addition, persons with previous CHD, otitis media surgery or diabetes were oversampled. Predefined age-dependent strata were made to ensure gender equilibrium and a 2:1 ratio of high risk:low risk participants according to the Berlin Questionnaire. Invitations were made by telephone, and 585 of the invited refused to participate, 202 were not reached after three attempts, and 28 persons were excluded. Exclusion criteria of the study included use of continuous positive airway pressure, physical impairment, pregnancy and insufficient Norwegian language skills. In the end, 535 (46.7\% of the contacted) persons participated in the clinical phase of the study, while 442 persons from the pool of 1772 were not contacted as the predefined strata were completed. Further details of the recruitment protocol have been described previously [19].

\section{Data collection}

All participants $(n=535)$ arrived at noon and stayed over-night at Akershus University Hospital, Stensby where collection of all of the data was performed.

\section{Blood sampling and analysis}

Fasting blood samples were collected from an antecubital vein in the morning, and were centrifuged within one hour. Serum samples were stored at $-20^{\circ} \mathrm{C}$ for a maximum of 20 days, before they were transported to the central biobank and frozen at $-80^{\circ} \mathrm{C}$ pending later measurements. Sampling and storing failed for 4 participants. hs-TnI was measured using the ARCHITECT STAT hs Troponin assay (Abbott Diagnostics, Illinois, USA) as previously reported [20]. NT-proBNP was measured by electrochemiluminescent immunoassay (Roche Diagnostics, Basel, Switzerland) with a lower detection limit of $5 \mathrm{pg} / \mathrm{ml}$. The hs-CRP measurements were performed using a latex immunoassay kit on a COBAS INTEGRA400 (Roche Diagnostics, Basel, Switzerland), with a lower detection limit of $0.1 \mathrm{pg} / \mathrm{mL}$. Analyses of biomarkers were not performed for 9 participants due to lack of available plasma. Creatinine, glucose and lipids were measured by standard laboratory methods. The creatinine clearance was estimated by the CockcroftGault formula [21].

\section{Electrocardiography}

All participants underwent an in-hospital 5-channel ambulatory electrocardiography (Medilog AR12, Oxford Instruments Medical, Surrey, United Kingdom) for assessment of cardiac arrhythmias. Recordings with a shorter duration than $10 \mathrm{~h}$, or with technical failure, were excluded from the analysis $(n=10)$. The mean length of the recordings was $18.3 \mathrm{~h}$. The electrocardiography recordings were 
automatically analyzed by a software engine (Medilog Darwin, ScanMed Medical, Gloucestershire, United Kingdom) according to predefined criteria. A premature ventricular complex (PVC) was defined as a N-V complex $>15 \%$ shorter than the previous $3 \mathrm{~N}-\mathrm{N}$ complexes. All PVC's were counted and dichotomized at a cut off of $5 / \mathrm{h}$. We defined complex ventricular ectopy as any bigeminy ( $\geq 3$ consecutive $\mathrm{V}-\mathrm{N}$ complexes), trigeminy ( $\geq 3$ consecutive $\mathrm{V}-\mathrm{N}-\mathrm{N}$ complexes), or nonsustained ventricular tachycardia $(\geq 3$ consecutive $\mathrm{V}$ complexes). One researcher, blinded for the participants' medical background and biomarker levels, manually reviewed and re-scored all recordings. A second researcher manually reviewed $10 \%$ of the recordings. The inter-rater correlation was 0.99. Examples of frequent PVC and complex ventricular ectopy are shown in Fig. 2.

\section{Demographic variables and cardiovascular risk factors}

The participants were asked about history of CHD (myocardial infarction or coronary artery revascularization), history of congestive heart failure, use of antihypertensive medication, diabetes mellitus and current smoking habits and underwent a standard physical examination. Blood pressure was measured in the sitting position after $15 \mathrm{~min}$ rest by an automatic device (Dinamap, ProCare 400, GE HealthCare, Milwaukee, WI, USA). The mean of the two last out of three recordings was calculated and used in analysis. The Sokolow-Lyon criteria were used for estimation of left ventricle hypertrophy [22]. Body mass index (weight in $\mathrm{kg} /$ height in meters squared) was calculated. The participants underwent inhospital polysomnography, as previously reported [19]. Data were manually scored using the Somnologica 3.2 software (Flaga-Medcare, Buffalo, New York), 13 registrations were not analyzed due to technical failure or short sleep duration. The apnea-hypopnea index (AHI) was calculated using the average number of apneas (airflow $<10 \%$ of reference in more than 10 s) plus hypopneas (airflow $<30 \%$ in more than 10 s and subsequent $\geq 4 \%$ fall in oxygen saturation) per hour of sleep.

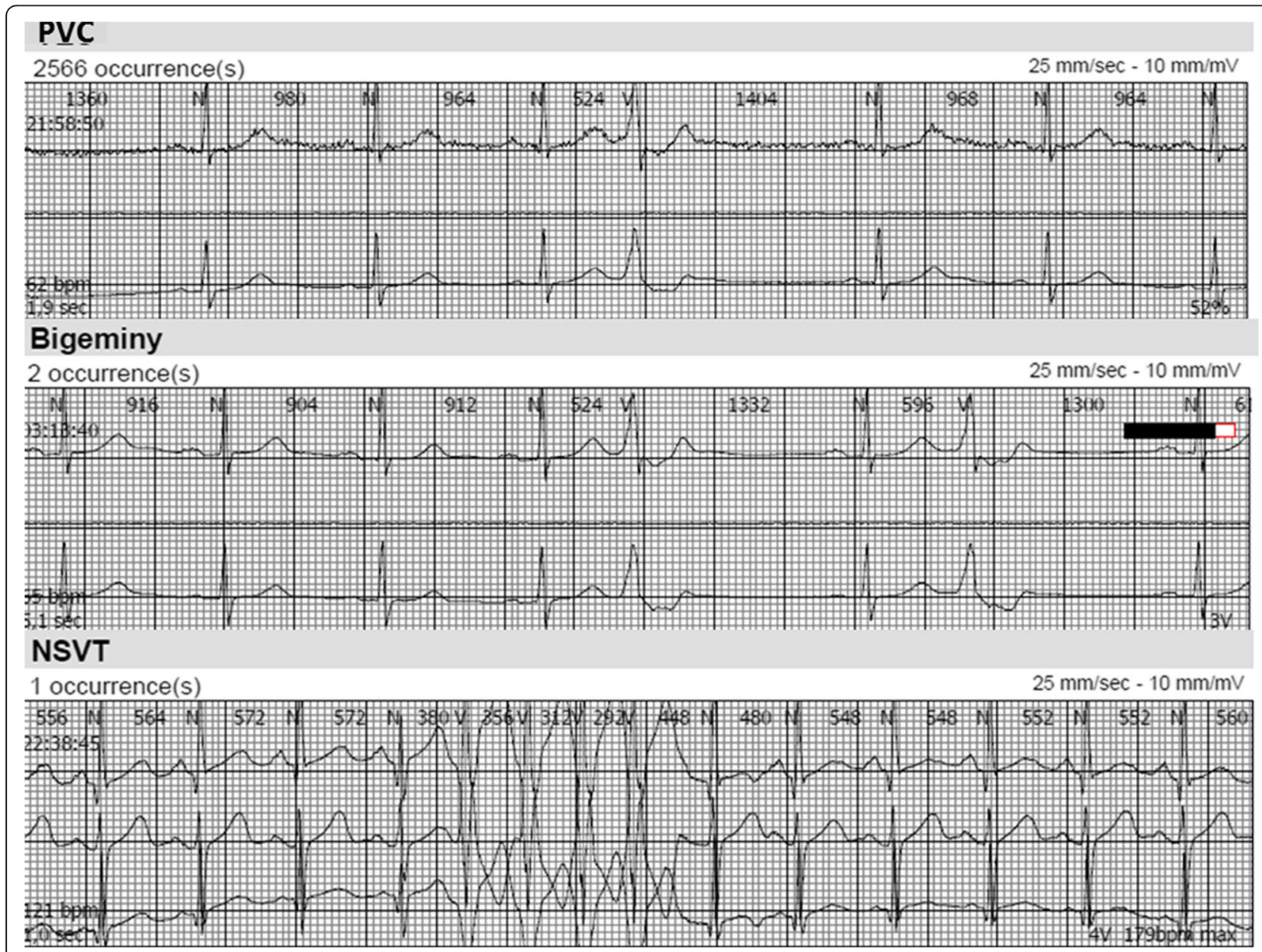

Fig. 2 Examples of premature ventricular contraction (PVC) and complex ventricular ectopy 
Table 1 Demographic and clinical characteristics in patients with and without $>5 \mathrm{PVC} / \mathrm{h}$

\begin{tabular}{|c|c|c|c|c|}
\hline & $<5 \mathrm{PVC} / \mathrm{h} n=452$ & $>5 \mathrm{PVC} / \mathrm{h} n=46$ & OR $(95 \% \mathrm{Cl})$ & $P$ \\
\hline Age (mean, SD) & $48(11)$ & $56(9)$ & $1.09(1.05-1.12)$ & $<0.001$ \\
\hline Male gender (n, \%) & $243(54)$ & $29(63)$ & $1.47(0.78-2.75)$ & 0.230 \\
\hline Current smoking $(\mathrm{n}, \%)$ & $121(27)$ & $11(25)$ & $0.89(0.44-1.81)$ & 0.742 \\
\hline History of coronary artery disease (n, \%) & $37(8)$ & $13(28)$ & $4.42(2.14-9.12)$ & $<0.001$ \\
\hline History of hypertension (n, \%) & $137(30)$ & $24(52)$ & $2.51(1.36-4.62)$ & 0.003 \\
\hline Diabetes mellitus (n, \%) & $52(12)$ & $7(15)$ & $1.38(0.59-3.25)$ & 0.460 \\
\hline Creatinine clearance (mean, SD) & $124(37)$ & $119(32)$ & $1.00(0.99-1.01)$ & 0.363 \\
\hline Systolic blood pressure, mm Hg (mean, SD) & $135(18)$ & $136(16)$ & $1.00(0.99-1.02)$ & 0.673 \\
\hline Body mass index (mean, SD) & $28.8(5.0)$ & $29.2(4.8)$ & $1.02(0.96-1.08)$ & 0.590 \\
\hline Cholesterol ratio (mean, SD) & $4.5(2.6)$ & $4.3(1.3)$ & $0.93(0.74-1.15)$ & 0.490 \\
\hline Left ventricular hypertrophy $(\mathrm{n}, \%)$ & $27(6)$ & $7(15)$ & $2.81(1.15-6.87)$ & 0.023 \\
\hline AHI (median, Q 1-3) & $5.7(1.5-16.9)$ & $12.4(6.9-40.6)$ & $1.65(1.30-2.09)$ & $<0.001$ \\
\hline
\end{tabular}

$A H I$ apnea-hypopnea index, $C l$ confidence interval, OR odds ratio, $P V C$ premature ventricular complexes, $Q$ quartiles, SD standard deviation

\section{Statistical analysis}

Due to skewed distribution of data, we transformed NTproBNP, hs-TnI, CRP and AHI concentrations logarithmically prior to the analysis. Categorical data are presented as absolute numbers and percentages, continuous data as mean (standard deviation) or median (interquartile range). The associations between biomarkers and ventricular arrhythmias were investigated by univariate and multivariate logistic regression analyses. According to a previous report from the same study, OSA may be associated with increased risk of PVC's [23], consequently we included the $\mathrm{AHI}$ as covariate in addition to the conventional cardiovascular risk factors (age, gender, history of CHD, history of diabetes, history of hypertension, body mass index, systolic blood pressure, total cholesterol:HDL cholesterol ratio). Covariates significantly $(p<0.05)$ associated with arrhythmias in univariate analyses were first entered into multivariate models.
The cardiovascular biomarkers were subsequently added to make separate multivariate models to evaluate whether hs-TnI, NT-proBNP or hs-CRP added significant incremental information to the regression models. The results are reported as odds ratio (OR) and 95\% confidence intervals $(\mathrm{CI})$ and a $p$ value $(2$-sided $)<0.05$ was considered statistically significant for all analyses. All statistical analyses were performed with the SPSS statistical software package, version 20 (SPSS Inc., Chicago, USA).

\section{Results}

\section{Patient characteristics}

A total of 498 participants had a complete data set in this substudy. More than $5 \mathrm{PVC} / \mathrm{h}$ were observed in 46 participants (9\%), while non-sustained ventricular arrhythmia, bigeminy and trigeminy were observed in 13, 26 and 27 participants, respectively. As 19 persons had more than

Table 2 Demographic and clinical characteristics in patients with and without complex ventricular ectopy

\begin{tabular}{|c|c|c|c|c|}
\hline & No complex $n=455$ & Any complex $n=47$ & OR $(95 \% \mathrm{Cl})$ & $P$ \\
\hline Age (mean, SD) & $48(11)$ & $56(9)$ & $1.08(1.05,1.11)$ & $<0.001$ \\
\hline Male gender $(n, \%)$ & $249(55)$ & $26(55)$ & $1.09(0.66,1.79)$ & 0.752 \\
\hline Current smoking $(\mathrm{n}, \%)$ & $121(27)$ & $11(23)$ & $0.84(0.47,1.50)$ & 0.552 \\
\hline History of coronary artery disease $(n, \%)$ & $38(8)$ & $12(26)$ & $3.65(1.91,6.96)$ & $<0.001$ \\
\hline History of hypertension ( $n, \%)$ & $144(32)$ & $20(43)$ & $1.96(1.18,3.26)$ & 0.009 \\
\hline Diabetes mellitus ( $\mathrm{n}, \%)$ & $57(13)$ & $3(6)$ & $0.92(0.42,2.03)$ & 0.838 \\
\hline Creatinine clearance (mean, SD) & $125(36)$ & $118(33)$ & $0.99(0.99,1.00)$ & 0.062 \\
\hline Systolic blood pressure, mm Hg (mean, SD) & $134(18)$ & $145(20)$ & $1.02(1.01,1.04)$ & 0.003 \\
\hline Body mass index (mean, SD) & $29(5)$ & $30(6)$ & $1.01(0.97,1.07)$ & 0.597 \\
\hline Cholesterol ratio (mean, SD) & $4.5(2.6)$ & $4.3(1.4)$ & $0.94(0.79,1.12)$ & 0.474 \\
\hline Left ventricular hypertrophy (n, \%) & $23(5)$ & $3(6)$ & $2.35(0.95,5.80)$ & 0.065 \\
\hline AHI (median, Q 1-3) & $5.9(1.6,17.1)$ & $12.1(6.0,36.0)$ & $1.42(1.18,1.72)$ & $<0.001$ \\
\hline
\end{tabular}

$\mathrm{AHI}$ apnea-hypopnea index, $\mathrm{Cl}$ confidence interval, $\mathrm{OR}$ odds ratio, $Q$ quartiles, $S D$ standard deviation 
one type of complex ventricular ectopy, a total number of 47 persons (9\%) had any complex ventricular ectopy.

Demographic and clinical characteristics according to the presence or absence of more than $5 \mathrm{PVC} / \mathrm{h}$ or any complex ventricular arrhythmia are summarized in Tables 1 and 2. No patients reported congestive heart failure.

\section{Association between biomarkers and ventricular arrhythmias}

We found higher concentrations of hs-TnI (3.0 vs. 1.4 ng/ $\mathrm{L}, p<0.001$ ) and NT-proBNP (75.7 vs. $41.3 \mathrm{pg} / \mathrm{mL}, p<$ 0.001 ) among the participants who had $>5$ PVC/h (Fig. 2). In contrast, hs-CRP concentrations did not differ between the two groups (1.0 vs. $1.2 \mathrm{mg} / \mathrm{L}, p=0.978)$. The concentrations of hs-TnI (3.0 vs. $1.4 \mathrm{ng} / \mathrm{L}, p<0.001)$ and NTproBNP (82.6 vs. $41.0 \mathrm{pg} / \mathrm{mL}, p<0.001$ ) were also higher among participants with complex ventricular ectopy compared to those without, while we found no difference for hs-CRP concentrations (1.1 vs. $1.2 \mathrm{mg} / \mathrm{L}, p=0.58$ ) (Fig. 3 ).

Age, history of CHD, history of hypertension, left ventricular hypertrophy and AHI were associated with frequent PVC's and included in the multivariate models (Table 3, Model 1). Each of the biomarkers hs-TnI (Model 2), NT-proBNP (Model 3) and hs-CRP (Model 4), was then added to the variables included in Model 1 . The association between NT-proBNP and $>5 \mathrm{PVC} / \mathrm{h}$ remained significant (OR 1.50 [95\% CI 1.07-2.12], $p=0.020$ ) in multivariate analyses, while the association between frequent PVC and hs-TnI was attenuated. NT-proBNP was also significantly associated with complex ventricular ectopy in analysis (OR 1.81 [1.27-2.57], $p=0.001$ ) that adjusted for age, history of CHD, systolic blood pressure and AHI. The association between complex ventricular ectopy and hs-TnI was attenuated and no longer statistical significant in multivariate analyses (Table 4).

\section{Discussion}

The main finding of the current study is that higher levels of NT-proBNP, but not hs-TnI or hs-CRP levels, are independently associated with the incidence of frequent ventricular ectopy and complex ventricular ectopy in a moderately large, community-based study population.

The present study assessed the relationship between two types of biomarkers for future CVD; low-level increments in circulating biomarkers and asymptomatic ventricular arrhythmias. We are aware of only one prior community-based study that reported higher unadjusted concentrations of NT-proBNP and CRP in persons with frequent PVC [17]. In that study, the combination of elevated CRP and frequent PVC increased the risk for future cardiovascular events, while NT-proBNP levels did not affect the association between frequent PVC and the outcomes. However, to the best of our knowledge, the associations between serum biomarkers and complex
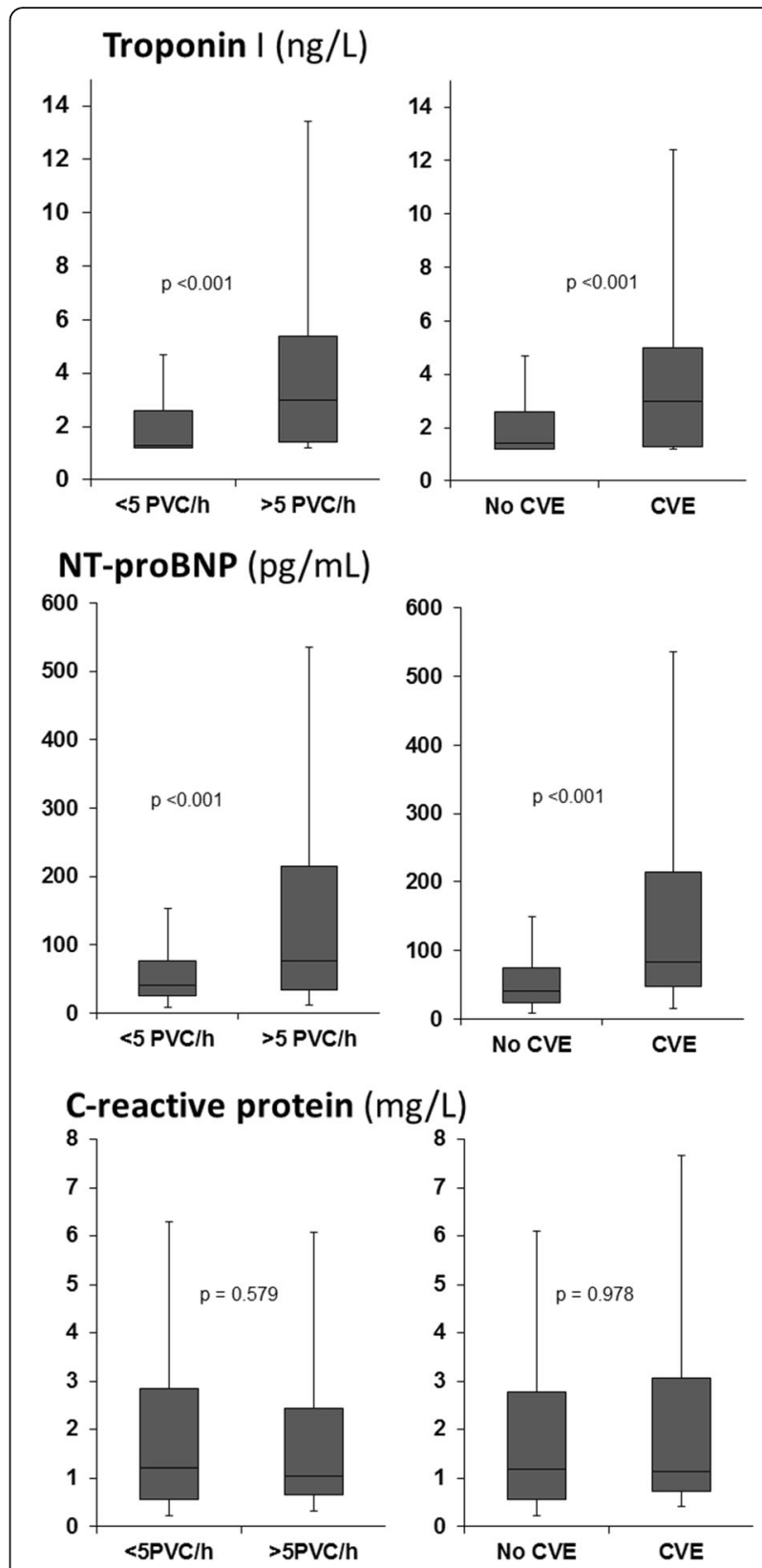

Fig. 3 Serum-concentrations of biomarkers in 498 participants according to the presence or absence of frequent PVCs or complex ventricular ectopy

ventricular ectopy as well as the association between cardiac troponins and asymptomatic ventricular arrhythmias, have not previously been studied. We report that the concentration of NT-proBNP is associated with increased risk for both frequent PVCs and complex ventricular arrhythmias such as non-sustained ventricular tachycardias, bigeminy and trigeminy, independent of traditional risk factors for CVD. Regarding hs-TnI, the increase in serum concentration observed in participants with ventricular ectopy was not significant after 
Table 3 Statistical significant determinants of $>5$ PVC/h, separate models for the 3 cardiovascular biomarkers. Multivariate logistic regression model, $n=498$

\begin{tabular}{|c|c|c|c|c|c|c|c|c|}
\hline & $\begin{array}{l}\text { Model } 1 \\
\text { OR (95\% Cl) }\end{array}$ & $P$ & $\begin{array}{l}\text { Model } 2 \\
\text { OR (95\% Cl) }\end{array}$ & $P$ & $\begin{array}{l}\text { Model } 3 \\
\text { OR (95\% Cl) }\end{array}$ & $P$ & $\begin{array}{l}\text { Model } 4 \\
\text { OR ( } 95 \% \text { Cl) }\end{array}$ & $P$ \\
\hline Age & $1.07(1.03-1.11)$ & 0.001 & $1.06(1.02-1.11)$ & 0.005 & $1.05(1.01-1.10)$ & 0.014 & $1.07(1.03-1.11)$ & 0.00 \\
\hline History of coronary heart disease & $2.80(1.17-6.76)$ & 0.021 & $2.52(1.03-6.19)$ & 0.044 & $2.00(0.77-5.15)$ & 0.152 & $2.76(1.14-6.70)$ & 0.025 \\
\hline History of hypertension & $0.76(0.34-1.66)$ & 0.486 & $0.76(0.34-1.67)$ & 0.489 & $0.76(0.34-1.68)$ & 0.491 & $0.77(0.45-1.70)$ & 0.511 \\
\hline AHI (events/h) & $1.41(1.08-1.83)$ & 0.010 & $1.37(1.05-1.78)$ & 0.019 & $1.46(1.12-1.90)$ & 0.006 & $1.42(1.09-1.85)$ & 0.01 \\
\hline Left ventricular hypertrophy & $2.84(1.07-7.57)$ & 0.037 & $2.69(1.00-7.26)$ & 0.051 & $3.06(1.13-8.32)$ & 0.028 & $2.82(1.06-7.53)$ & 0.039 \\
\hline log hs-CRP (mg/L) & & & & & & & $0.96(0.69-1.33)$ & 0.785 \\
\hline log NT-proBNP (pg/mL) & & & & & $1.50(1.07-2.12)$ & 0.020 & & \\
\hline log hs-Tnl (ng/L) & & & $1.32(0.86-2.03)$ & 0.205 & & & & \\
\hline
\end{tabular}

hs-CRP, NT-proBNP and hs-Tnl were transformed by logarithm before regression analysis

$A H I$ apnea-hypopnea index, $C l$ confidence interval, $h s C R P$ high-sensitive C-reactive protein, $h s-T n l$ high-sensitive cardiac Troponin I, NT-proBNP N-terminal proB-type natriuretic peptide, OR odds ratio, PVC premature ventricular complexes

adjustment for established hypertension, CHD, ECGcalculated left ventricular hypertrophy and AHI. In contrast to Sajadieh et al., we found no association between the inflammatory marker hs-CRP and any type of ventricular arrhythmia.

Different mechanisms may account for the association between NT-proBNP and ventricular arrhythmias. Left ventricular hypertrophy and mild left ventricular dysfunction are important determinants of low-level increments of both NT-proBNP and cardiac troponins [6], and are also associated with the risk of arrhythmias. Sub-clinical myocardial scarring and diffuse fibrosis may also cause both increased levels of cardiac markers as well as substrates for ventricular arrhythmias [24]. In contrast, subclinical myocardial inflammation, at least as reflected by hs-CRP concentrations, did not explain the tendency toward ventricular arrhythmias in our community-based cohort of relatively young subjects. The increase of circulating NT-proBNP could also be a result of the arrhythmia itself. However, as the observed arrhythmias were short-lasting and asymptomatic in this study, we find it unlikely that the arrhythmia itself has increased the NT-proBNP concentrations. Finally, recent data from the ASAP study suggest that the severity of OSA, as expressed by the AHI, could be independently associated with both asymptomatic arrhythmias [23] and troponin I [25]. At the time of preparation of the previous manuscript regarding frequent PVC's, data concerning troponin I and NT-proBNP were not available, but the present data suggest that, at least for NT-proBNP, $\mathrm{AHI}$ is not the underlying mechanism.

A strength of this study is the community-based design and sample size. The generalizability is limited by the inclusion procedure, biasing participants with high weight, hypertension, snoring and daytime sleepiness. Thus, the risk factor profile current cohort is not reflective of the general population. Statistic procedures have been made to adjust for the presence of sleep apnea and $\mathrm{CV}$ risk factors. The lack of echocardiographic measures, particularly of left ventricular function, is another limitation of this study. Cardiac imaging data could potentially have added further information to the analysis; however, we included electrocardiographic signs of left ventricular hypertrophy in the study.

Table 4 Statistical significant determinants of complex ventricular ectopy, separate models for the 3 cardiovascular biomarkers. Multivariate logistic regression model, $n=498$

\begin{tabular}{|c|c|c|c|c|c|c|c|c|}
\hline & $\begin{array}{l}\text { Model } 1 \\
\text { OR }(95 \% \text { Cl) }\end{array}$ & $P$ & $\begin{array}{l}\text { Model } 2 \\
\text { OR }(95 \% \mathrm{Cl})\end{array}$ & $P$ & $\begin{array}{l}\text { Model } 3 \\
\text { OR (95\% Cl) }\end{array}$ & $P$ & $\begin{array}{l}\text { Model } 4 \\
\text { OR }(95 \% \mathrm{Cl})\end{array}$ & $P$ \\
\hline Age & $1.06(1.02-1.10)$ & 0.003 & $1.06(1.02-1.10)$ & 0.007 & $1.04(0.99-1.08)$ & 0.091 & $1.06(1.02-1.10)$ & 0.003 \\
\hline History of coronary artery disease & $2.48(1.14-5.39)$ & 0.022 & $2.29(1.02-5.14)$ & 0.044 & $1.49(0.63-3.56)$ & 0.365 & $2.50(1.14-5.46)$ & 0.022 \\
\hline Systolic blood pressure (mmHg) & $1.02(1.00-1.04)$ & 0.033 & $1.02(1.00-1.04)$ & 0.057 & $1.02(1.00-1.04)$ & 0.037 & $1.02(1.00-1.04)$ & 0.034 \\
\hline $\mathrm{AHI}$ (events/h) & $1.20(0.95-1.51)$ & 0.130 & $1.18(0.93-1.50)$ & 0.165 & $1.25(0.98-1.58)$ & 0.072 & $1.19(0.94-1.51)$ & 0.149 \\
\hline $\log$ hs-CRP (mg/L) & & & & & & & $1.04(0.76-1.44)$ & 0.801 \\
\hline $\log$ NT-proBNP (pg/mL) & & & & & $1.81(1.27-2.57)$ & 0.001 & & \\
\hline log hs-Tnl (ng/L) & & & $1.18(0.76-1.81)$ & 0.467 & & & & \\
\hline
\end{tabular}

hs-CRP, NT-proBNP and hs-Tnl were transformed by logarithm before regression analysis

$A H I$ apnea-hypopnea index, $C l$ confidence interval, $h s-C R P$ high-sensitive C-reactive protein, $h s$ - $T n l$ high-sensitive cardiac Troponin I, NT-proBNP N-terminal proB-type natriuretic peptide, $O R$ odds ratio 
It is debated whether ventricular ectopy is an independent risk marker of mortality. In patients with established cardiac disease, the association may be explained by other established risk factors [26], while a recent report from a community-based study suggests that PVC's predict HF and mortality [27]. The current study indicates that circulating biomarkers that assess lowlevel cardiac damage not detected by measures of ejection fraction ought to be included when investigating the prognostic influence by ventricular ectopy.

\section{Conclusions}

In this study we demonstrate that the level of NTproBNP is independently associated with frequent PVCs and complex ventricular ectopy, although none of the biomarkers examined are specific biomarkers of asymptomatic ventricular arrhythmias. We suggest that these relationships points to underlying mechanisms, not accounted for in traditional CV risk factors, which may contribute to the association between these biomarkers and $\mathrm{CV}$ death observed in the general population.

\section{Additional file}

Additional file 1: Data set. (XLSX $60 \mathrm{~kb})$

\section{Abbreviations}

AHI: Apnea-hypopnea index; ASAP: Akershus Sleep Apnea Project; BNP: Btype natriuretic peptide; CHD: Coronary heart disease; Cl: Confidence intervals; CRP: C-reactive protein; CV: Cardiovascular; HF: Heart failure; hs: High sensitivity; hs-Tnl: high sensitivity-troponin I; NT: N-terminal; NTproBNP: N-terminal pro-B-type natriuretic peptide; OR: odds ratio; OSA: Obstructive sleep apnea; PVC: Premature ventricular complexes; Q: Quartiles; SD: Standard deviation

\section{Acknowledgments}

We acknowledge the contributions by all study personnel that contributed to the ASAP Study, Marit Holmefjord Pedersen for the hs-Tnl analysis, and Susann Brunell for the NT-proBNP analysis.

\section{Funding}

This study has been supported by the South-Eastern Norway Regional Health Authority (grant number 2004219, 2007048), and the University of Oslo. Abbott Diagnostics has provided the reagents for the hs-Tnl-assay.

\section{Availability of data and materials}

The dataset supporting the conclusions of this article is included within the article and its Additional file 1.

\section{Authors' contributions}

All authors read and approved the final manuscript. JBS: conducted the analysis and interpretation of data, GE: was involved in planning the design, collecting the data, interpretation of data and writing the manuscript. AR, SKN, HH-S were involved in planning the design and collecting the data. JB were involved in the data collection. T-AH, VKS participated in planning the design. HR was involved in writing the manuscript. TO had the idea of the study, main responsible for planning of the design, interpretation of data and writing of the manuscript.

\section{Competing interests}

TO has received speaker and/or consultancy honoraria from Abbott Diagnostics, Roche Diagnostics, Novartis and research support from Abbott Diagnostics, AstraZeneca, Thermo Fisher Scientific, and Biomedica. GE has received research grants from Astra Zeneca and speaker honorarium from Takeda. The other authors declare no reported conflicts of interest.

Consent for publication

Not applicable.

Ethics approval and consent to participate

The study was approved by the regional ethics committee and performed according to the Declaration of Helsinki. Written informed consent was obtained from all participants before study commencement.

\section{Author details}

'Division of Medicine, Akershus University Hospital, Lørenskog, Norway. ${ }^{2}$ Asker and Bærum Emergency Unit, Sandvika, Norway. ${ }^{3}$ Division of Surgery, Akershus University Hospital, Lørenskog, Norge. ${ }^{4}$ Division of Diagnostics and Technology, Akershus University Hospital, Lørenskog, Norway. ${ }^{5}$ Division of Cardiovascular Diseases, Department of Internal Medicine, Mayo Foundation for Medical Education and Research, Rochester, MN, USA. ${ }^{6}$ Institute of Clinical Medicine, University of Oslo, Oslo, Norway.

Received: 3 April 2016 Accepted: 11 November 2016

Published online: 22 November 2016

\section{References}

1. Omland T. New features of troponin testing in different clinical settings. J Intern Med. 2010;268(3):207-17.

2. Omland T. Advances in congestive heart failure management in the intensive care unit: B-type natriuretic peptides in evaluation of acute heart failure. Crit Care Med. 2008;36(1 Suppl):S17-27.

3. de Lemos JA. Increasingly sensitive assays for cardiac troponins: a review. JAMA. 2013;309(21):2262-9.

4. Omland T, de Lemos JA, Sabatine MS, Christophi CA, Rice MM, Jablonski KA Tjora S, Domanski MJ, Gersh BJ, Rouleau JL, et al. A sensitive cardiac troponin T assay in stable coronary artery disease. N Engl J Med. 2009; 361(26):2538-47.

5. Omland T. Cardiac troponins: a tool for a personalized medicine strategy in stable coronary artery disease? J Am Coll Cardiol. 2014;63(4):355-7.

6. de Lemos JA, Drazner MH, Omland T, Ayers CR, Khera A, Rohatgi A, Hashim I, Berry JD, Das SR, Morrow DA, et al. Association of troponin T detected with a highly sensitive assay and cardiac structure and mortality risk in the general population. JAMA. 2010;304(22):2503-12.

7. Saunders JT, Nambi V, de Lemos JA, Chambless LE, Virani SS, Boerwinkle E, Hoogeveen RC, Liu X, Astor BC, Mosley TH, et al. Cardiac troponin T measured by a highly sensitive assay predicts coronary heart disease, heart failure, and mortality in the Atherosclerosis Risk in Communities Study. Circulation. 2011;123(13):1367-76.

8. Wang TJ, Larson MG, Levy D, Benjamin EJ, Leip EP, Omland T, Wolf PA, Vasan RS. Plasma natriuretic peptide levels and the risk of cardiovascular events and death. N Engl J Med. 2004;350(7):655-63.

9. Danesh J, Wheeler JG, Hirschfield GM, Eda S, Eiriksdottir G, Rumley A, Lowe GDO, Pepys MB, Gudnason V. C-reactive protein and other circulating markers of inflammation in the prediction of coronary heart disease. N Engl J Med. 2004;350(14):1387-97.

10. Wang TJ, Wollert KC, Larson MG, Coglianese E, McCabe EL, Cheng S, Ho JE, Fradley MG, Ghorbani A, Xanthakis V, et al. Prognostic utility of novel biomarkers of cardiovascular stress: the Framingham Heart Study. Circulation. 2012;126(13):1596-604.

11. Go AS, Mozaffarian D, Roger VL, Benjamin EJ, Berry JD, Blaha MJ, Dai S, Ford ES, Fox CS, Franco $S$, et al. Executive summary: heart disease and stroke statistics-2014 update: a report from the American Heart Association. Circulation. 2014;129(3):399-410.

12. Myerburg RJ, Junttila MJ. Sudden cardiac death caused by coronary heart disease. Circulation. 2012:125(8):1043-52.

13. Stecker EC, Vickers C, Waltz J, Socoteanu C, John BT, Mariani R, McAnulty JH, Gunson K, Jui J, Chugh SS. Population-based analysis of sudden cardiac death with and without left ventricular systolic dysfunction: two-year findings from the Oregon Sudden Unexpected Death Study. J Am Coll Cardiol. 2006;47(6):1161-6.

14. Simpson Jr RJ, Cascio WE, Schreiner PJ, Crow RS, Rautaharju PM, Heiss G. Prevalence of premature ventricular contractions in a population of African 
American and white men and women: the Atherosclerosis Risk in Communities (ARIC) study. Am Heart J. 2002;143(3):535-40.

15. Massing MW, Simpson Jr RJ, Rautaharju PM, Schreiner PJ, Crow R, Heiss G. Usefulness of ventricular premature complexes to predict coronary heart disease events and mortality (from the Atherosclerosis Risk In Communities cohort). Am J Cardiol. 2006;98(12):1609-12.

16. Ataklte F, Erqou S, Laukkanen J, Kaptoge S. Meta-analysis of ventricular premature complexes and their relation to cardiac mortality in general populations. Am J Cardiol. 2013;112(8):1263-70.

17. Sajadieh A, Nielsen OW, Rasmussen V, Ole Hein H, Hansen JF. Increased ventricular ectopic activity in relation to C-reactive protein, and NT-probrain natriuretic peptide in subjects with no apparent heart disease. Pacing Clin Electrophysiol. 2006;29(11):1188-94.

18. Netzer NC, Stoohs RA, Netzer CM, Clark K, Strohl KP. Using the Berlin Questionnaire to identify patients at risk for the sleep apnea syndrome. Ann Intern Med. 1999;131(7):485-91.

19. Hrubos-Strom H, Randby A, Namtvedt SK, Kristiansen HA, Einvik G, Benth J, Somers VK, Nordhus IH, Russell MB, Dammen T, et al. A Norwegian populationbased study on the risk and prevalence of obstructive sleep apnea. The Akershus Sleep Apnea Project (ASAP). J Sleep Res. 2011;20(1 Pt 2):162-70

20. Rosjo H, Kravdal G, Hoiseth AD, Jorgensen M, Badr P, Roysland R, Omland T. Troponin I measured by a high-sensitivity assay in patients with suspected reversible myocardial ischemia: data from the Akershus Cardiac Examination (ACE) 1 study. Clin Chem. 2012;58(11):1565-73.

21. Cockcroft DW, Gault MH. Prediction of creatinine clearance from serum creatinine. Nephron. 1976;16(1):31-41.

22. Sokolow M, Lyon TP. The ventricular complex in right ventricular hypertrophy as obtained by unipolar precordial and limb leads. Am Heart J. 1949;38(2):273-94

23. Namtvedt SK, Randby A, Einvik G, Hrubos-Strom H, Somers VK, Rosjo H, Omland T. Cardiac arrhythmias in obstructive sleep apnea (from the Akershus Sleep Apnea Project). Am J Cardiol. 2011;108(8):1141-6.

24. Chin CW, Shah AS, McAllister DA, Joanna Cowell S, Alam S, Langrish JP, Strachan FE, Hunter AL, Maria Choy A, Lang CC, et al. High-sensitivity troponin I concentrations are a marker of an advanced hypertrophic response and adverse outcomes in patients with aortic stenosis. Eur Heart J. 2014:35(34):2312-21.

25. Einvik G, Rosjo H, Randby A, Namtvedt SK, Hrubos-Strom H, Brynildsen J, Somers VK, Omland T. Severity of obstructive sleep apnea is associated with cardiac troponin I concentrations in a community-based sample: data from the akershus sleep apnea project. Sleep. 2014;37(6):1111-6.

26. Seth N, Kaplan R, Bustamante E, Kulkarni C, Subacius H, Rosenthal JE, Passman R. Clinical significance of nonsustained ventricular tachycardia on routine monitoring of pacemaker patients. Pacing Clin Electrophysiol. 2015;38(8):980-8.

27. Dukes JW, Dewland TA, Vittinghoff E, Mandyam MC, Heckbert SR, Siscovick DS, Stein PK, Psaty BM, Sotoodehnia N, Gottdiener JS, et al. Ventricular ectopy as a predictor of heart failure and death. J Am Coll Cardiol. 2015;66(2):101-9.

\section{Submit your next manuscript to BioMed Central and we will help you at every step:}

- We accept pre-submission inquiries

- Our selector tool helps you to find the most relevant journal

- We provide round the clock customer support

- Convenient online submission

- Thorough peer review

- Inclusion in PubMed and all major indexing services

- Maximum visibility for your research

Submit your manuscript at www.biomedcentral.com/submit

) Biomed Central 